\title{
Changes in the subgingival biofilm composition after coronally positioned flap
}

\author{
Jadson Almeida LIMA', Vanessa Renata SANTOS ${ }^{2}$, Magda FERES ${ }^{3}$, Luciene Cristina de FIGUEIREDO4, \\ Poliana Mendes DUARTE ${ }^{4}$
}

1- DDS, MSc student, Department of Periodontics, Dental Research Division, Guarulhos University, Guarulhos, SP, Brazil.
2- DDS, MSc, PhD student, Department of Periodontics, Dental Research Division, Guarulhos University, Guarulhos, SP, Brazil.
3- DDS, MSc, PhD, Chair, Department of Periodontics, Dental Research Division, Guarulhos University, Guarulhos, SP, Brazil.
4- DDS, MSc, PhD, Assistant Professor, Department of Periodontics, Dental Research Division, Guarulhos University, Guarulhos, SP, Brazil.

Corresponding address: Poliana Mendes Duarte - Praça Teresa Cristina, n. 229 - Centro - Guarulhos - 07.023-070 - SP - Phone/Fax: + 55-11-2464-1758 e-mail: poliduarte@yahoo.com / pduarte@ung.br

Received: September 6, 2009 - Modification: April 30, 2010 - Accepted: May 25, 2010

\section{ABSTRACT}

$\mathrm{O}$ bjectives: This study evaluated the effects of coronally positioned flap (CPF) on the subgingival biofilm composition. Material and Methods: Twenty-two subjects with gingival recessions were treated with CPF. Clinical parameters were assessed before and at 6 months after surgery. Subgingival biofilms were analyzed by checkerboard DNADNA hybridization technique for 40 bacterial species. Results: Recession height, clinical attachment level and bleeding on probing improved significantly $(p<0.05)$ at 6 months postCPF. The proportions of 10 periodontal pathogens and the proportions of red and orange complexes decreased at 6 months. Conclusion: In conclusion, CPF can induce beneficial effects on the composition of the subgingival microbiota after 6 months.

Key words: Bacteria. Microbiology. DNA probes.

\section{INTRODUCTION}

It has been well documented that the exposure of root surfaces as a result of gingival recession may result in tactile and thermal sensitivity, esthetic complaints ${ }^{5}$, and root surface carious lesions ${ }^{19}$. Numerous longitudinal human studies have demonstrated the efficacy and predictability of different techniques to esthetically, as well as functionally, correct gingival recession ${ }^{27}$. Among the various techniques employed to correct gingival exposure, the coronally positioned flap (CPF), alone or combined with other procedures, e.g. subepithelial connective tissue graft (SCTG), has been one of the most widely used procedures in the treatment of Miller Class I gingival recessions ${ }^{2,9,14}$. The coverage percentage of a previously exposed root surface is the primary clinical outcome used to evaluate the effectiveness of a mucogingival procedure. A high level of success, ranging from $60 \%$ to $99 \%$ of root coverage, has been reported after CPF in Miller Class I and II recessions with appropriate case selection ${ }^{18,20,27}$. Miller ${ }^{16}$ (1988) suggested that a successful plastic procedure for root coverage should also provide shallow sulcus and no bleeding on probing ${ }^{16}$. In general, reestablishment of esthetic and reduction of dentine sensitivity are the greatest advantages for patients that receive a plastic surgery for recession coverage.

To date, reports have only focused on the clinical outcomes of the mucogingival procedures to correct gingival recessions. To our knowledge the effects of these procedures on the composition of subgingival microbiota have not been investigated. Thus, the aim of this study was to evaluate whether the treatment of gingival recession with a coronally positioned flap (CPF) could interfere with the subgingival biofilm composition at 6 months after surgery.

\section{MATERIAL AND METHODS}

Twenty-two non-smoking, non-pregnant or lactant, periodontally and systemically healthy subjects from the Periodontics Department of Guarulhos University were enrolled in this study (January 2006 to June 2006). The following inclusion criteria were used: 1 -Subjects with one Miller Class I gingival recession defect ( $\geq 2 \mathrm{~mm}$ and $\leq 4 \mathrm{~mm}$ ) in 
upper canines or premolars; 2- Keratinized tissue height of at least $2 \mathrm{~mm}$; 3 - Probing depth $\leq 2 \mathrm{~mm}$; 4- Absence of caries or restorations in the area to be treated; 5- Absence of pulpal pathology and severe occlusal interferences in the teeth to be treated; 6Radiographic evidence of sufficient interdental bone; 7- Full-mouth plaque index ${ }^{1}$ and full-mouth bleeding on probing index scores of $\leq 20 \%$; 8 - Absence of previous mucogingival surgery at the defect; 9Dental hypersensitivity and/or impaired esthetics associated with the recession.

Patients were informed of the characteristics of the study and gave their written consent to the described procedures. The study protocol was previously approved by the Institutional Committee of Ethics in Dental Research, in accordance with the Helsinki Declaration of 1975.

\section{Coronally-Positioned Flap}

The patients were submitted to CPF procedures, performed by one of the researches. Right before the surgery, the exposure root surfaces were mechanically treated with manual curettes. After local anesthesia (2\% lidocaine with 1:100000 epinephrine), a sulcular incision was carried out at the buccal aspect and two horizontal incisions were made at right angles to the adjacent papillae. Subsequently, two divergent oblique incisions at the mesial and distal aspects of the recession, apically extending beyond mucogingival junction (MGJ), completed a trapezoidal flap design. A periosteal elevator was used to carefully reflect an initial fullthickness flap until the mucogingival junction. After the mucogingival junction, a split thickness flap was dissected mesially, distally and apically, as necessary to release any tissue tension. The papillae adjacent to the involved tooth were deepithelialized. The flap was coronally displaced, completely covering the recession and fixed with a non-resorbable suture and a mattress sling suturing technique. Finally, interrupted sutures were placed at the vertical incisions to facilitate tissue stabilization. Subjects were instructed not to brush the teeth in the treated area but to rinse with chlorhexidine gluconate $(0.12 \%)$ mouthwash twice a day for 2 weeks. Analgesics were prescribed to control postoperative discomfort. The sutures were removed after 14 days and, at teeth with recession-type defects, a coronally roll technique was prescribed.

\section{Clinical Parameters}

The following parameters were assessed on the buccal aspect of all studied teeth at baseline and at 6 months after the surgeries using a manual probe (UNC15, Hu-Friedy, Chicago, IL, USA): 1- Local plaque score $(P L)^{1}$ : presence $(1)$ or absence $(0)$ assessed using a manual periodontal probe; 2 - Local bleeding on probing (BOP): presence (1) or absence
(0) of bleeding of up to 15 seconds after gentle probing; 3- Probing depth (PD): distance between the gingival margin (GM) and the bottom of the gingival sulcus; 4- Recession height $(\mathrm{RH})$ : distance between cemento-enamel junction to the most apical point of the GM; 5- Clinical attachment level ( $C A L)$ : distance between cemento-enamel junction to the bottom of the gingival sulcus; 6 - Keratinized tissue height $(\mathrm{KH})$ : distance between the most apical extension of GM to the MGJ, chemically disclosed with Schiller's iodine solution; 7-Keratinized tissue thickness (KT): measured at a mid-point location between GM and MGJ by penetrating the probe into the tissue and recorded to the nearest $0.5 \mathrm{~mm}$.

The assessed clinical parameters were arranged in order to obtain: A- Recession reduction (RR): calculated as [preoperative $\mathrm{RH}$ - postoperative $\mathrm{RH}$ ]; $\mathrm{B}-\mathrm{CAL}$ gain (CALG): calculated as preoperative CAL - postoperative CAL; C- Percentage of root coverage (RC): calculated as [preoperative $\mathrm{RH}$ - postoperative $\mathrm{RH}]$ / preoperative $\mathrm{RH} \times 100$. The clinical parameters were assessed by the same periodontist who was trained and calibrated (s.e.m.=0.014).

\section{Microbiologic Assessment \\ Sample collection}

After removing the supragingival biofilm with sterile cotton pellets, subgingival biofilm samples were collected from the mid-buccal aspect of each experimental tooth using sterile curettes (5-6 miniGracey curette; UNC15, Hu-Friedy) and immediately placed in separate Microtubes containing $0.15 \mathrm{~mL}$ TE (10 mM Tris- $\mathrm{HCl}, 1 \mathrm{mM}$ EDTA, $\mathrm{pH}$ 7.6). Freshly prepared $0.5 \mathrm{M} \mathrm{NaOH}(0.1 \mathrm{~mL})$ was then added to each tube and the samples were dispersed using a vortex mixer. Biofilm samples were collected from the same sites at baseline and 6 months after CPF procedures.

\section{Checkerboard DNA-DNA hybridization}

Counts of 40 bacterial species were determined in each sample, using the checkerboard DNADNA hybridization technique ${ }^{24}$. The analyses were performed at the Laboratory of Microbiology of Guarulhos University as previously described by Matarazzo, et al. ${ }^{15}$ (2008). The 40 reference strains used to develop the DNA probes are presented in Figure 1 according to bacterial complexes ${ }^{21-22}$.

\section{Statistical Analysis}

Data were analyzed using a software (SAS for Windows V8, SAS Institute Cary, Cary, NC, USA). First, the Kolmogorov-Smirnov test was used to evaluate the normality of the data. The frequency of detection of BOP (1) and PL (1) was determined for each period. The statistical significance of the differences for BOP (1) and PL (1) over time was evaluated by Chi-square and Fisher tests. In 


\begin{tabular}{|c|c|c|c|}
\hline Species & Strain & Species & Strain \\
\hline Blue complex & & Orange complex & \\
\hline Actinomyces gerencseriae & $23860 a$ & Eubacterium nodatum & $33099 a$ \\
\hline Actinomyces israelii & $12102 a$ & Fusobacterium nucleatum ss. nucleatum & $25586 a$ \\
\hline Actinomyces naes/undii sp.1 & $12104 a$ & Fusobacterium nucleatum ss. polymorphum & $10953 a$ \\
\hline Actinomyces naeslundii sp. 2 & $43146 a$ & Fusobacterium nucleatum ss. vincentii & $49256 a$ \\
\hline $\begin{array}{l}\text { Purple complex } \\
\end{array}$ & & Fusobacterium periodonticum & $33693 a$ \\
\hline Actinomyces odontolyticus & $17929 a$ & Parvimonas micra & $33270 a$ \\
\hline Veillonella parvula & $10790 a$ & Prevotella intermédia & $25611 a$ \\
\hline $\begin{array}{r}\text { Yellow complex } \\
\end{array}$ & & Prevotella nigrescens & $33563 a$ \\
\hline Streptococcus gordonii & $10558 a$ & Streptococcus constellatus & $27823 a$ \\
\hline Streptococcus intermedius & $27335 a$ & Red complex & \\
\hline Streptococcus mitis & $49456 a$ & Tannerella forsythia & $43037 a$ \\
\hline Streptococcus oralis & $35037 a$ & Porphyromonas gingivalis & $33277 a$ \\
\hline Streptococcus sanguinis & $10556 a$ & Treponema denticola & $\mathrm{B} 1 \mathrm{~b}$ \\
\hline Green complex & & Other species & \\
\hline Aggregatibacter actinomycetemcomitans $a+b$ & $43718 / 29523 \mathrm{a}$ & Eubacterium saburreum & $33271 a$ \\
\hline Capnocytophaga gingivalis & $33624 a$ & Gemella morbillorum & $27824 a$ \\
\hline Capnocytophaga ochracea & $33596 a$ & Leptotrichia buccalis & $14201 a$ \\
\hline Capnocytophaga sputigena & $33612 a$ & Prevotella melaninogenica & $25845 a$ \\
\hline Eikenella corrodens & $23834 a$ & Propionibacterium acnes & $11827 / 11828 a$ \\
\hline Orange complex & & Selenomonas noxia & $43541 a$ \\
\hline Campylobacter gracilis & $33236 a$ & Streptococcus anginosus & $33397 a$ \\
\hline Campylobacter rectus & $33238 a$ & Treponema socranskii & $\mathrm{S} 1 \mathrm{~b}$ \\
\hline Campylobacter showae & $51146 a$ & Neisseria mucosa & $19696 \mathrm{a}$ \\
\hline
\end{tabular}

Figure 1- Bacterial strains employed for the development of the DNA probes

a- ATCC (American Type Collection, Rockville, MD); b- Forsyth Institute, Boston, MA

addition, Wilcoxon test was carried out to evaluate changes in PD, KT, KH, RH and CAL.

The proportions of each species and of each microbial complex were determined for each experimental site and averaged within baseline and six-month periods. The significance of differences between baseline and 6 months in mean proportion of each species and of the different microbial complexes was determined using the Wilcoxon signed-rank test.

Adjustments were made for multiple comparisons as described by Socransky, et al. ${ }^{23}$ (1991) when the mean proportions of individual species were evaluated. The significance level established for all analyses was $5 \%(p<0.05)$.

\section{RESULTS}

Twenty-two patients, 18 females and 4 males, aged between 25 and 60 years (mean age $42.66 \pm 12.01$ ) were included in the present study. Twenty-two maxillary Miller Class I gingival recession defects, one from each patient, were treated: 4 right canines, 1 left canine, 8 right first premolars, 7 left first premolars and 2 left second premolars.

The mean values of the clinical parameters at baseline and at 6 months post-surgery are summarized in Table 1 . No significant differences were observed for PD, KT and KH ( $p>0.05)$ between experimental periods. In addition, no significant changes in the frequencies of $\mathrm{PL}$ were observed
Table 1- Clinical parameters at baseline and at 6 months after coronally positioned flap

\begin{tabular}{lcc}
\hline Clinical parameters & BASELINE & 6 MONTHS \\
\hline PD $(\mathrm{mm})$ & $1.4 \pm 0.5$ & $1.2 \pm 0.5$ \\
KT $(\mathrm{mm})$ & $0.93 \pm 0.34$ & $0.88 \pm 0.28$ \\
KH $(\mathrm{mm})$ & $3.18 \pm 0.91$ & $3.40 \pm 0.94$ \\
RH $(\mathrm{mm})$ & $2.75 \pm 0.55^{\mathrm{a}}$ & $0.55 \pm 0.69^{\mathrm{b}}$ \\
\hline $\mathrm{CAL}(\mathrm{mm})$ & $4.13 \pm 0.72^{\mathrm{a}}$ & $1.75 \pm 0.91^{\mathrm{b}}$ \\
Number of site with: & & \\
PL & 12 & 7 \\
BOP & $9^{\mathrm{a}}$ & $0^{\mathrm{b}}$ \\
\hline
\end{tabular}

Data are means \pm standard deviation. No statistically significant differences for $\mathrm{PD}, \mathrm{KT}$ and $\mathrm{KH}$ were determined by Wilcoxon test $(p>0.05)$. Different letters $(a, b)$ mean differences for $\mathrm{RH}$ and CAL determined by Wilcoxon test $(p=0.0001)$ and for BOP determined by the Chi-square or Fisher tests between the two time points. No statistically significant differences for PL was found by Chi-square or Fisher tests $(p>0.05)$.

PD- probing depth; KT-keratinized tissue thickness; $\mathrm{KH}$ keratinized tissue height; $\mathrm{RH}$-recession height; $\mathrm{CAL}$-clinical attachment level; plaque accumulation (PL); bleeding on probing (BOP).

between baseline and six months ( $p>0.05)$. RH, CAL and BOP levels improved significantly at 6 months 
$\%$ DNA PROBE COUNTS

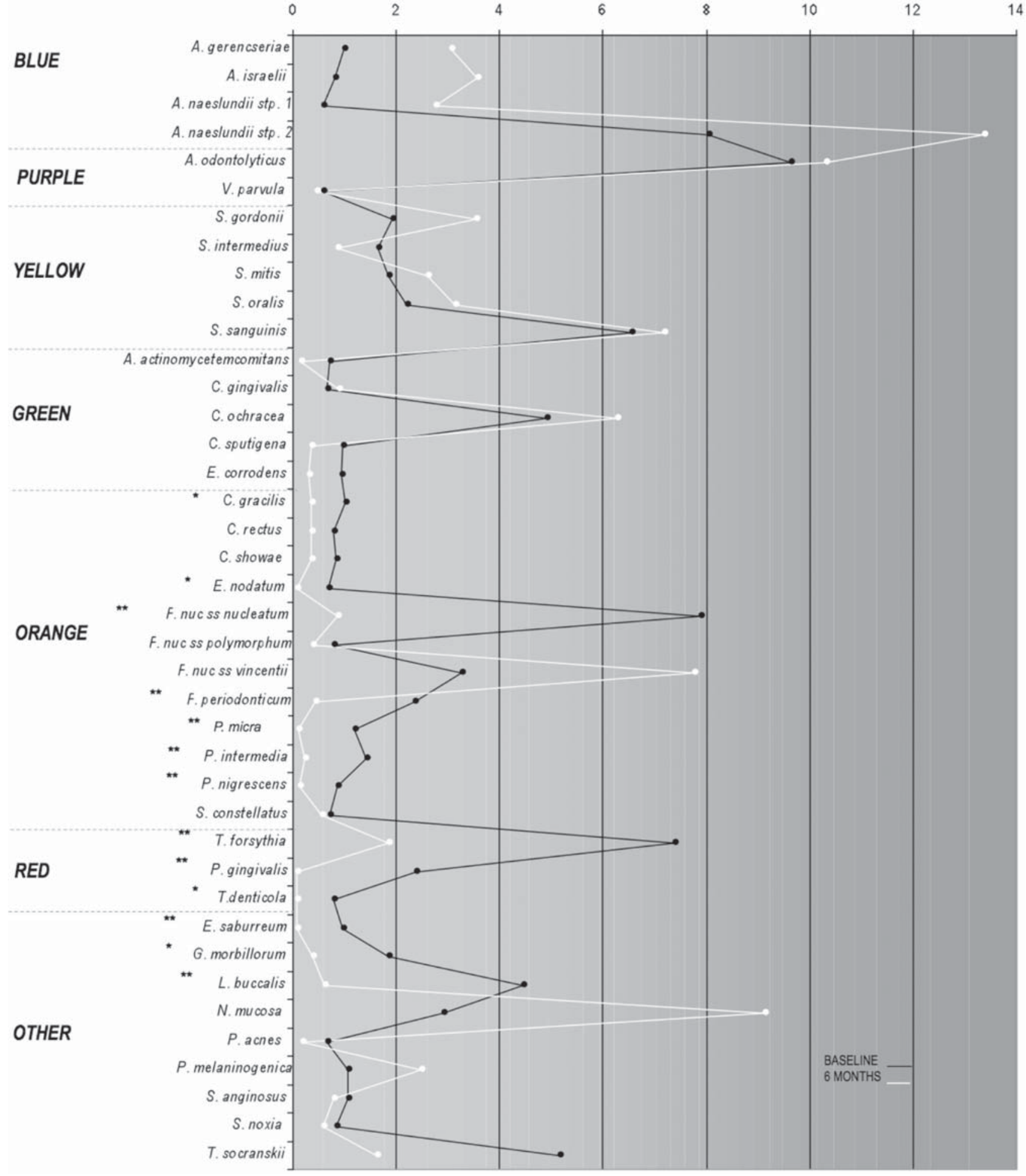

Figure 2- Mean proportions of 40 subgingival bacterial species at baseline and at 6 months after coronally positioned flap. The significance of differences in mean proportions between baseline and 6 months for each species was tested using the Wilcoxon signed-rank test after adjusting for multiple comparisons $\left({ }^{*}=p<0.05,{ }^{* *}=p<0.01\right)$. The black line represents the mean data at baseline and the white line represents the mean data at 6 months post-surgery

$(p<0.05)$.

At six months, the mean RR, CALG and RC were respectively, $2.2 \pm 0.6,2.4 \pm 1.0$ and $81.64 \% \pm 21 \%$. Twelve sites (55\%) achieved complete RC, 7 sites (32\%) reached from $60 \%$ to $100 \%$ and only 3 sites
(13\%) showed less than $60 \%$ of coverage.

The mean proportions of the 40 species evaluated in subgingival biofilm at baseline and at 6 months after CPF are presented in Figure 2. The results revealed that the proportions of 13 species 


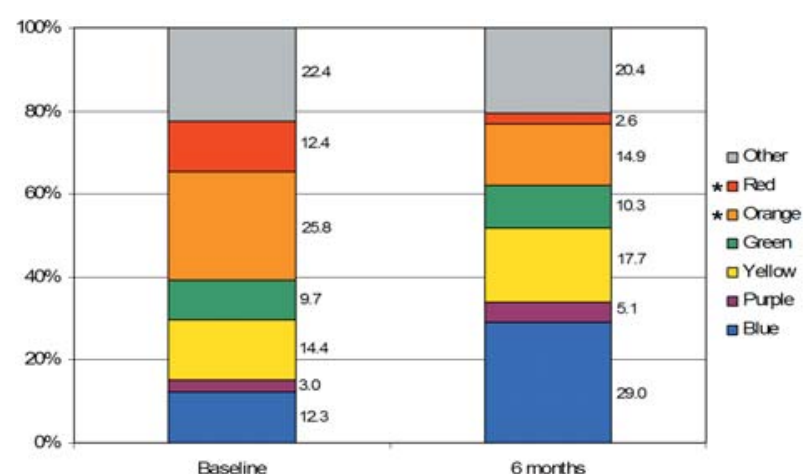

Figure 3- Mean proportions of microbial complexes (12) at baseline and at 6 months after coronally positioned flap. The significance of differences was tested using the Wilcoxon signed-rank test $\left({ }^{*}=p<0.05\right)$

decreased at 6 months after surgery $(p<0.05)$, including 3 pathogens of the red complex (Tannerella forsythia, Porphyromonas gingivalis, Treponema denticola) and 7 putative periodontal pathogens of the orange complex (Fusobacterium periodonticum, Parvimonas micra, Prevotella intermedia, Prevotella nigrescens, Eubacterium nodatum, Fusobacterium ss. nucleatum nucleatum and Campylobacter gracilis) There was also a trend towards an increase in the proportion of some beneficial microorganisms of the blue, purple, and yellow complexes, such as Actinomyces gerencseriae, Actinomyces israelii, Actinomyces naes/undii 1 and 2, Streptococcus gordonii, Streptococcus mitis and Streptococcus oralis.

Mean proportions of microbial complexes at baseline and at 6 months after CPF are presented in Figure 3. A significant decrease in the proportion of red (from $12.4 \%$ to $2.6 \%$ ) and orange (from 25.8 $\%$ to $14.9 \%$ ) complexes was observed at 6 months after CPF $(p<0.05)$. A tendency for an increase in the proportion of beneficial complexes (blue, purple, yellow and green) was also observed post-therapy. This was particularly noted for the blue complex, which accounted for $12.3 \%$ of the evaluated species at baseline and for $29 \%$ at 6 months after CPF.

\section{DISCUSSION}

Despite the common clinical application of periodontal plastic therapies, to our knowledge, no study to date has described the microbiological impact of these treatments. Therefore, this is the first study to evaluate whether the treatment of gingival recession with a CPF could influence the subgingival biofilm composition at 6 months following surgery. In addition, CPF clinical effectiveness was determined as a function of root coverage percentage and periodontal tissue health.

It has been recognized that the success of a periodontal plastic procedure is reached when the gingival margin is at the cemento-enamel junction with sulcus depth $\leq 2 \mathrm{~mm}$, no bleeding on probing and with presence of remained clinically attached gingiva ${ }^{17}$. In the present study, the exposed root surfaces demonstrated improvements in clinical outcomes in terms of recession height reduction $(R R)$, clinical attachment gain (CALG), shallow probing depth $(1.2 \pm 0.5)$, reduced frequency of bleeding on probing (BOP) and unchanged KT and $\mathrm{KH}$ at 6 months post-surgery. In addition, as previously described ${ }^{2-3,10}$, the mean percentage of root coverage $(81.64 \% \pm 21 \%)$ observed in the present study confirmed that CPF is a predictable procedure to treat Miller Class I mucogingival defects.

Reports describing the composition of subgingival biofilm associated with gingival recessions are very scarce. A previous report demonstrated that subgingival biofilm of buccal sites with progressive gingival recession is colonized by gram positive species and, therefore, the microbiota resembled that of healthy sites. None of the predominant species, including $A$. naes/undii, $S$. oralis and $A$. israelli has been described as periodontal pathogens ${ }^{26}$. These microbiological data are consistent with clinical and epidemiological observations that suggest a major traumatic, not infectious, etiology for gingival recessions ${ }^{4,11}$. Contrary to the abovementioned findings ${ }^{26}$, in the present study, some of the predominant species observed on subgingival biofilm of the initially selected recessions, including $T$. forsythia and $F$. nucleatum ss. nucleatum, have been described as periodontal pathogens ${ }^{12,22,24,28}$. A possible explanation for these contradictory results may be the fact that, in contrast to the aforementioned study ${ }^{26}$ that found no recessions with BOP, $45 \%$ of our recessions presented BOP on the beginning of the study. Various microbiological studies have reported a range of gram negative species at bleeding sites, including $F$. nuclealum species, $T$. forsythia, $P$. intermedia, $P$. nigrescens and $P$. gingivalis ${ }^{6,25-26}$. Additionally, it has been recognized that the three red complex species ( $T$. forsythia, $P$. gingivalis, $T$. denticola) and various species of the orange complex are related to the presence of $\mathrm{BOP}^{7,21}$.

In addition to BOP reduction and CALG, our longitudinal analyses demonstrated a decrease in the proportion of some pathogens and a trend for an increase in the proportions of health-associated microorganisms after CPF. Although the presence of BOP is not a reliable predictor or indicator for additional periodontal attachment $\operatorname{loss}^{7-8,13}$, it has been demonstrated that the presence of some periodontal pathogens (e.g. T. forsythia) may be associated with sites converting to periodontal disease ${ }^{7}$. Thus, the microbial changes observed in the subgingival biofilm after CPF, especially those 
related to the reduction of pathogens, seem to be a previously unreported advantage of mucogingival therapy. One could argue that these microbial changes would be related to the oral hygiene instruction and not to the CPF. Because of ethical reasons, we did not include a contralateral tooth that received only hygiene instruction to observe the effect of brushing technique alone on the subgingival composition. Although it was not observed a statistically significant reduction on visible plaque accumulation at 6 months post-surgery, we speculated that our clinical and microbiological findings could be due to the improvement of hygiene in the treated areas due to the surgery. Some hypothesis can be made in a attempt to explain the improvement of biofilm control after CPF: the reduction of dentin hypersensitivity; the shift of the gingival margin from apical to coronal position that could aid the brushing of the dento-gingival interface of the treated teeth; the increased motivation for hygiene since the volunteers were enrolled in a clinical study; and/or the fact that the subjects were submitted to a surgical procedure and, thus, they were concerned in preserving the initial benefits achieved.

\section{CONCLUSION}

It may be concluded that coronally positioned flap can have a beneficial effect on the composition of the subgingival microbiota, reducing the periodontal pathogen proportions in a six-month evaluation, maybe by the improvement of hygiene control in the treated area. Thus, besides to the esthetic improvement and the possible reduction in sensitivity, favorable changes in the subgingival biofilm adjacent to the gingival tissue seem to be an additional advantage for coronally positioned flap.

\section{REFERENCES}

1- Ainamo J, Bay I. Problems and proposals for recording gingivitis and plaque. Int Dent J. 1975;25:229-35.

2- Allen EP, Miller PD Jr. Coronal positioning of existing gingiva: short term results in the treatment of shallow marginal tissue recession. J Periodontol. 1989;60:316-9.

3- Baldi C, Pini-Prato G, Pagliaro U, Nieri M, Saletta D, Muzzi L, et al. Coronally advanced flap procedure for root coverage. Is flap thickness a relevant predictor to achieve root coverage? A 19-case series. J Periodontol. 1999;70:1077-84.

4- Beck JD, Koch GG. Characteristics of older adults experiencing periodontal attachment loss as gingival recession or probing depth. J Periodontal Res. 1994;29:290-8.

5- Bouchard P, Malet J, Borghetti A. Decision-making in aesthetics: root coverage revisited. Periodontol 2000. 2001;27:97-120.

6- Gmür R, Strub JR, Guggenheim B. Prevalence of Bacteroides forsythus and Bacteroides gingivalis in subgingival plaque of prosthodontically treated patients on short recall. J Periodontal Res. 1989;24:113-20.

7- Haffajee AD, Cugini MA, Tanner A, Pollack RP, Smith C, Kent RL $\mathrm{Jr}$, et al. Subgingival microbiota in healthy, well-maintained elder and periodontitis subjects. J Clin Periodontol. 1998;25:346-53.
8- Haffajee AD, Socransky SS, Lindhe J, Kent RL, Okamoto $\mathrm{H}$, Yoneyama T. Clinical risk indicators for periodontal attachment loss. J Clin Periodontol. 1991;18:117-25.

9- Harris RJ, Harris AW. The coronally positioned pedicle graft with inlaid margins: a predictable method of obtaining root coverage of shallow defects. Int J Periodontics Restorative Dent. 1994;14:22841.

10- Huang LH, Neiva RE, Wang HL. Factors affecting the outcomes of coronally advanced flap root coverage procedure. J Periodontol. 2005; 76:1729-34.

11- Joshipura KJ, Kent RL, DePaola PF. Gingival recession: intra-oral distribution and associated factors. J Periodontol. 1994;65:864-71. 12- Klein MI, Goncalves RB. Detection of Tannerella forsythensis (Bacteroides forsythus) and Porphyromonas gingivalis by polymerase chain reaction in subjects with different periodontal status. J Periodontol. 2003;74:798-802.

13- Lang NP, Adler R, Joss A, Nyman S. Absence of bleeding on probing. An indicator of periodontal stability. J Clin Periodontol. $1990 ; 17: 714-21$

14- Langer B, Langer L. Subepithelial connective tissue graft technique for root coverage. J Periodontol. 1985;56:715-20.

15- Matarazzo F, Figueiredo LC, Cruz SE, Faveri M, Feres M. Clinical and microbiological benefits of systemic metronidazole and amoxicillin in the treatment of smokers with chronic periodontitis: a randomized placebo-controlled study. J Clin Periodontol. 2008;35:885-96.

16- Miller PD Jr. Regenerative and reconstructive periodontal plastic surgery. Mucogingival surgery. Dent Clin North Am. 1988;32:287306.

17- Miller PD Jr. Root coverage with the free gingival graft. Factors associated with incomplete coverage. J Periodontol. 1987;58:67481.

18- Pagliaro U, Nieri M, Franceschi D, Clauser C, Pini-Prato G. Evidence-based mucogingival therapy. Part 1: A critical review of the literature on root coverage procedures. J Periodontol. $2003 ; 74: 709-40$.

19- Seichter U. Root surface caries: a critical literature review. J Am Dent Assoc. 1987;115:305-10.

20- Silva RC, Joly JC, Lima AF, Tatakis DN. Root coverage using the coronally positioned flap with or without a subepithelial connective tissue graft. J Periodontol. 2004;75:413-9.

21- Socransky SS, Haffajee AD. Periodontal microbial ecology. Periodontol 2000. 2005;38:135-87.

22- Socransky SS, Haffajee AD, Cugini MA, Smith C, Kent RL Jr. Microbial complexes in subgingival plaque. J Clin Periodontol. $1998 ; 25: 134-44$.

23- Socransky SS, Haffajee AD, Smith C, Dibart S. Relation of counts of microbial species to clinical status at the sampled site. J Clin Periodontol. 1991;18:766-75.

24- Socransky SS, Smith C, Martin L, Paster BJ, Dewhirst FE, Levin AE. "Checkerboard" DNA-DNA hybridization. Biotechniques. $1994 ; 17: 788-92$.

25- Tanner A, Kent R, Maiden MF, Taubman MA. Clinical, microbiological and immunological profile of healthy, gingivitis and putative active periodontal subjects. J Periodontal Res. 1996;31:195-204.

26- Tanner A, Maiden MF, Macuch PJ, Murray LL, Kent RL Jr. Microbiota of health, gingivitis, and initial periodontitis. J Clin Periodontol. 1998;25:85-98.

27- Wennström JL. Mucogingival therapy. Ann Periodontol. $1996 ; 1: 671-701$.

28- Yang HW, Huang YF, Chou MY. Occurrence of Porphyromonas gingivalis and Tannerella forsythensis in periodontally diseased and healthy subjects. J Periodontol. 2004;75:1077-83. 